\title{
Kinetics of the dissolution of sand into alkaline solutions: application of a modified shrinking core model
}

\author{
A. Mgaidi ${ }^{\mathrm{a}, *}$, F. Jendoubi ${ }^{\mathrm{a}}$, D. Oulahna ${ }^{\mathrm{b}}$, M. El Maaoui ${ }^{\mathrm{a}}$, J.A. Dodds ${ }^{\mathrm{b}}$ \\ ${ }^{a}$ Industrial Inorganic Chemistry Laboratory, Chemistry Department, Faculty of Sciences, Tunis 1060, Tunisia \\ ${ }^{\mathrm{b}}$ Laboratoire de Génie des Procédés des Solides Divisés-U.M.R. CNRS 2392-Ecole des Mines d'Albi Carmaux, \\ Campus Jarlard-Route de Teillet 81013 Albi, France
}

\begin{abstract}
The batch dissolution kinetics of sand particles in concentrated alkaline sodium hydroxide solutions was investigated at high temperature and high pressure. The influence of the particle size, the operating temperature $\left(150-220{ }^{\circ} \mathrm{C}\right)$ and the hydroxide ion molality on the kinetic rate were studied. Experimental data fit well into a developed model based on the shrinking core model approach in which a variable activation energy term was introduced. Kinetic analysis of the experimental results reveals that the associated energy and the rate-controlling mechanism are dependent upon both sample temperature as well as the extent of the reaction.
\end{abstract}

Keywords: Sand dissolution; Kinetics; Shrinking core model; Activation energy; Mechanism

\section{Introduction}

Noncatalytic heterogeneous reactions in solid-liquid systems are numerous and of great industrial importance. The reaction rate, the particle size distribution, the particles' shape and their complete conversion time into fluid phase are significant parameters for process design progress (Levenspiel, 1972; Villermaux, 1982).

Reactions in which the action of acid solutions on phosphate rock (for the production of phosphate fertilizers) and the dissolution of sand into sodium hydroxide solutions (for the production of sodium silicate) have been extensively studied establishing kinetic curves (Jendoubi et al., 1997, 1998; Ben Brahim et al., 1997, 1999).

In particular, few papers on kinetic modelling of dissolution of sand into sodium hydroxide solutions under the operating conditions of the wet process (high temperature and high pressure) seem to be published. Moreover, the analysis of the literature shows that many models have been proposed to describe kinetic data in no catalytically heterogeneous reactions. Mathematical models based on the unsteady-continuity equation for a reagent species, in spherical coordinates, have been applied to describe the leaching of several minerals (Bartlett, 1973; Dixon and Hendrix, 1993). The reaction zone model was shown to fit experimentally leaching data over a wide 
range of particle sizes and shapes and has subsequently been used as basis for modelling in situ leaching process (Lubej et al., 1999).

Lakatos and Blickle (1990) proposed a model based on the population balance approach to account for the influence of particle size distribution in their kinetic model for noncatalytic liquid-solid reactions. However, no comparison between the experimental results and the computed data was presented.

Some kinetic models proposed in the literature, such as homogeneous model, uniform pore model, grain model and shrinking core model were tested by Georgiou and Papangelakis (1998) to describe the sulfuric acid pressure leaching of a limonitic laterite. The authors proposed the grain model to describe nickel dissolution kinetics. This model needs some characteristics of the solid particles such as particle radius, molar density and porosity. Experimental data for the reaction between solid lime and gaseous $\mathrm{HCl}$ at low temperature have been fitted by Fonseca et al. (1998) using the grain model. This model was successfully used for a solid that is made up of small nonporous grains, and each of these grains reacted according to the unreacted core model. We can assume that the kinetic models reported are too simple, they did not take into account the change of the solid texture with time and they could only be applicable within the limits of their experiments.

Since 1972, Levenspiel (1972 and references therein) proposed the unreacted core model to fit some kinetic data for noncatalytic solid-liquid reactions. On the basis of studies of numerous systems, the author concludes that the shrinking core model is the best simple representation for the majority of industrial solid-fluid reactions. Since no ash is formed at any time during reaction, we have a case of kinetics of shrinking particle, and the appropriate term to be used is "shrinking unreacted particle model" instead of "shrinking core model": Under chemical reaction control, these two terms are identical (Levenspiel, 1972).

The shrinking core model was successfully applied (Greg et al., 2000) to fit the kinetics of extraction of gold(I), silver(I) and Ni(II) cyanide complexes from novel anion exchange resins. However, it is reported by Rahman and Al-Saleh (1999) that the kinetic leaching data of Raney-Ag alloy of different particle sizes into $\mathrm{NaOH}$ solutions failed to fit in the shrinking unreacted particle model. A modified shrinking model was proposed by Yoshioka et al. (2001) to study the kinetics of hydrolysis of polyethylene terephthalate powder in sulfuric acid. The authors assumed that the effective surface area was proportional to the degree of degradation of the sample.

Studying copper extraction by hydrochloric acid, Brittan (1975) proposed the so-called "Variable Activation Energy Shrinking Core Model" (VAESCM), in which the change of the activation energy as the reaction proceeds was taken into account. Vegliò et al. $(2001 \mathrm{a}, \mathrm{b})$ proposed and used the approach of a variable activation energy on the shrinking core model to describe the kinetics of the manganese acid dissolution under different experimental conditions $(30 \leq$ $T \leq 70 ; 75 \leq$ particle size $\leq 250 \mu \mathrm{m}$ ).

In this paper, a modified shrinking particle model has been proposed to describe the kinetic of dissolution of sand into alkaline solutions under experimental conditions $\left(150 \leq T \leq 220{ }^{\circ} \mathrm{C}\right.$ and $0.47 \leq P \leq 2.29$ $\mathrm{MPa}$ ) close to those in the industry of the wet-process sodium silicate production. The attention was directed to the effect of particle size on the reaction rate. The experimental kinetic data were analyzed in order to determine the controlling mechanisms and the underlying the equations.

\section{Theoretical considerations}

According to the ratio $\mathrm{SiO}_{2} / \mathrm{Na}_{2} \mathrm{O}$ used in this work, the reaction of dissolution of sand in $\mathrm{NaOH}$ solution could be represented by

$2 \mathrm{SiO}_{2 \text { (solid) }}+\mathrm{Na}_{2} \mathrm{O}-\mathrm{Na}_{2} \mathrm{Si}_{2} \mathrm{O}_{5}$

The fractional amount dissolved was calculated using the following equation:

$\alpha=\left\{\frac{\text { amount of } \mathrm{SiO}_{2} \text { dissolved }}{\text { total amount of } \mathrm{SiO}_{2} \text { present in the sand }}\right\}$

When the rate-limiting step is a surface reaction, the reaction rate is usually given by expression of the form

$m_{0} \frac{\mathrm{d} \alpha}{\mathrm{d} t}=v k^{\circ} S C_{0}^{b} \exp \left(-\frac{E_{\mathrm{a}}}{R T}\right)$ 
where $\alpha=$ extent of dissolution (dimensionless), $m_{0}=$ initial mass of sand $(\mathrm{g}), t=$ reaction time $(\mathrm{min})$, $k^{\circ}=$ a constant factor, $S=$ surface area $\left(\mathrm{cm}^{2} \mathrm{~g}^{-1}\right)$, $E_{\mathrm{a}}=$ activation energy $\left(\mathrm{J} \mathrm{mol}^{-1}\right), C_{0}=$ the hydroxide ion molality $\left(\mathrm{mol} \mathrm{cm}{ }^{-3}\right), b=$ the reaction order with the respect to the ion hydroxide, $v=$ stoichiometric coefficient, $R$ and $T$ the universal gas constant and the absolute temperature.

Using the standard formulation of the shrinking core model (for spherical particles) here, the ion hydroxide molality is considered constant during the chemical reaction, the time required for the conversion $\alpha$ is given by

$1-(1-\alpha)^{1 / 3}=t / \tau$

For spherical solid with radius $R_{\mathrm{p}}$ dissolved according to the surface chemical reaction control, the complete dissolution time (noted $\tau$ ) will be expressed as follows:

$\tau=\frac{R_{\mathrm{p}} \rho_{\mathrm{SiO}_{2}}}{v k C_{\mathrm{OH}^{-}}^{b}}$

where $\rho_{\mathrm{SiO}_{2}}$ is the sand true density in $\mathrm{g} \mathrm{cm}^{-3}, R_{\mathrm{p}}$ is the mean particle radius in centimeters and $k$ is the rate constant $\left(\mathrm{mol} \mathrm{min}{ }^{-1}\right)$. In this case, if the shrinking core model is valid, the complete conversion time $\tau$ is given by the slope of the straight line $1-(1-\alpha)^{1 / 3}$ against reaction time.

Considering the variable activation energy term proposed by Brittan (1975) and utilized by Vegliò et al. (2001a) in the modelling of manganiferous ore leaching, the kinetic expression of the sand dissolution has been written as

$$
\begin{aligned}
\frac{\mathrm{d} \alpha}{\mathrm{d} t}= & \frac{a_{1}}{R_{\mathrm{p}}} \exp \left[-\left(\frac{E_{\mathrm{a}}}{R}\left(\frac{1}{T}-\frac{1}{T^{\prime}}\right)+\frac{a_{2} \alpha_{3}^{a}}{R T}\right)\right] \\
& \times\left(C_{\mathrm{OH}^{-}}^{0}-C_{\mathrm{OH}^{-}}^{\mathrm{st}} \alpha\right)^{b}(1-\alpha)^{2 / 3}
\end{aligned}
$$

where $a_{1}, a_{2}, a_{3}$ and $b$ are adjustable parameters; $a_{1}$ is constant $\left(\mu \mathrm{m} \mathrm{M}^{-b} \min ^{-1}\right) ; a_{2}$ and $a_{3}$ are parameters relating the dissolution extent to the activation energy ( $a_{2}$ is in $\mathrm{kJ} \mathrm{mol}^{-1}$ and $a_{3}$ is dimensionless). $C_{\mathrm{OH}^{-}}^{\mathrm{st}}$, the stoichiometric hydroxide ion molality requirement according to Eq. (1), was calculated by

$C_{\mathrm{OH}^{-}}^{\mathrm{st}}=\frac{[\mathrm{mg} / \mathrm{L}]\left[\% \mathrm{SiO}_{2} \text { content for each size fraction }\right]}{100 \times M_{\mathrm{SiO}_{2}}}$
The reference temperature $T^{\prime}$ was calculated as suggested elsewhere (Vegliò et al., 2001a) and was introduced in the model to reduce the correlation between the activation energy and the preexponential parameter in the Arrhenius expression. All adjustable parameters can be estimated by a nonlinear regression analysis procedure.

\section{Experimental section}

\subsection{Materials}

The sand used in the study was provided from the Bou Argoub region of Tunisia. The sample was sieved using ASTM standard sieves, giving particle size fractions of $(+100,-125),(+300,-315),(+400$, $-500)$ and $(+850,-1000) \mu \mathrm{m}$.

Dissolution tests were carried out in stainless steel autoclave of $250-\mathrm{ml}$ capacity placed into a tubular furnace. The autoclave and furnace are equipped with swinging agitator system and heated using the electrical heating. The temperature was regulated at $\pm 1{ }^{\circ} \mathrm{C}$ and checked with a ChromelAlumel thermocouple.

Amount of reagents (sodium hydroxide solution and sand powder with composition of $99.2 \%$ of $\mathrm{SiO}_{2}$ ) corresponding to the reaction stoichiometry were introduced at room temperature, and the autoclave was closed and allowed to heat up to the desired temperature. The heating phase lasted about $30 \mathrm{~min}$ before the temperature reached $220{ }^{\circ} \mathrm{C}$.

\subsection{Definition and analysis}

To quantify the effects of the meaningful factors on the silica dissolution into sodium hydroxide solution, the particle size, the reactant molality and the temperature were chosen as parameters. Table 1 represents the selected experimental conditions used in this work.

During each experiment, the reaction time was noted from the moment when the autoclave reached the selected temperature. This time has been defined as "apparent reaction time," since the dissolution has already began during the heating phase. Preliminary experiments have shown that the reaction was detectable at about $150{ }^{\circ} \mathrm{C}$. 
Table 1

Experimental dissolution conditions used in this work

\begin{tabular}{lllll}
\hline $\begin{array}{l}\text { Test } \\
\text { number }\end{array}$ & $\begin{array}{l}\text { Particle size } \\
\left(R_{\mathrm{p}} \mu \mathrm{m}\right)\end{array}$ & $T\left({ }^{\circ} \mathrm{C}\right)$ & $\begin{array}{l}\text { Initial } \mathrm{OH}^{-} \\
\text {molality } \\
\left(\mathrm{mol} \mathrm{kg}^{-1}\right)\end{array}$ & $\begin{array}{l}\text { Number of } \\
\text { experimental } \\
\text { points }\end{array}$ \\
\hline 1 & 153.75 & 220 & 12.5 & 7 \\
2 & 153.75 & 200 & 12.5 & 6 \\
3 & 153.75 & 180 & 12.5 & 6 \\
4 & 153.75 & 150 & 12.5 & 4 \\
5 & 153.75 & 220 & 8.0 & 8 \\
6 & 153.75 & 220 & 3.0 & 8 \\
7 & 153.75 & 220 & 0.5 & 8 \\
8 & 56.25 & 220 & 12.5 & 10 \\
9 & 225.00 & 220 & 12.5 & 9 \\
10 & 462.25 & 220 & 12.5 & 10 \\
\hline
\end{tabular}

At the end of reaction period, the slurry was filtered, and the remaining solid was washed, dried in an oven at $60{ }^{\circ} \mathrm{C}$ and weighed. The dissolution extent was calculated according to the expression (2).

The true densities of some solid samples before and after a dissolution time (see Table 2 for overall parameters and range employed in experiments) were measured by volume displacement using an Accupyc 1330 Helium micrometric pycnometer. Specific surface areas were measured by Argon adsorption at LN2 temperature $(77 \mathrm{~K})$ using BET method. Before measurement, each sample had been degassed at 100 ${ }^{\circ} \mathrm{C}$ for about $4 \mathrm{~h}$. The particle size distribution was measured by laser diffraction using a MasterSizer Malvern 2000 apparatus. Finally, the raw and remaining sand collected were photographed under appropriate magnifications using a scanning electron microscope.

Table 2

Physical characterizations of solid samples used in experiments (initial conditions: $R_{\mathrm{p}}=153.75 \mu \mathrm{m}, T=180{ }^{\circ} \mathrm{C}$ and initial $\mathrm{OH}^{-}$ molality $=12.5 \mathrm{~mol} \mathrm{~kg}^{-1}$ )

\begin{tabular}{lccc}
\hline Parameters & \multicolumn{3}{c}{ Selected parameters values } \\
\hline Apparent leaching time $(\mathrm{min})$ & 0 & 30 & 60 \\
True density $\rho_{\mathrm{SiO}_{2}}\left(\mathrm{~g} / \mathrm{cm}^{3}\right)$ & 2.6025 & 2.5948 & 2.6170 \\
Surface area $S_{\mathrm{BET}}\left(\mathrm{m}^{2} / \mathrm{g}\right)$ & 0.5267 & 0.1029 & 0.7103 \\
$\begin{array}{l}\text { Pore diameter } 4 \mathrm{~V} / \mathrm{A}(\AA) \\
\quad \text { by BET }\end{array}$ & 125.6 & 110.0 & 110.4 \\
$\begin{array}{l}\text { Mean particle diameter } \\
\quad 2 R_{\mathrm{p}}(\mu \mathrm{m})\end{array}$ & 320 & 280 & 240 \\
\hline
\end{tabular}

\section{Results and discussion}

\subsection{Ore characterisation}

In Table 2, we reported values of the true density, mean particle diameter and the specific surface area for unreacted and residue solids obtained at different stages of reaction. As seen from this table, the true density was not affected by the reaction progress, the mean value was assumed to be on the order of magnitude of $2.6047 \mathrm{~g} \mathrm{~cm}^{-3}$. However, the mean particle diameter (according to laser diffraction measurement) decreased from 320 to $240 \mu \mathrm{m}$ after $1 \mathrm{~h}$ of dissolution.

Studying the Ottowa sand, particle size fraction 590-850 $\mu \mathrm{m}$, Worley et al. (1996) noted the difference between the geometric and BET surfaces areas. The $S_{\mathrm{BET}}$ was $325 \mathrm{~m}^{2} \mathrm{~g}^{-1}$, and the geometric one was $32 \mathrm{~cm}^{2} \mathrm{~g}^{-1}$. In our case, as it can be seen from Table 2 that there was no appreciable evolution of the surface area during the dissolution. The $S_{\mathrm{BET}}$ obtained in this work was in the order of magnitude of $0.5 \mathrm{~m}^{2}$ $\mathrm{g}^{-1}$, a small value but not negligible. The geometric surface area is much lower than the BET surface area that leads to the conclusion that the particles have a relatively important internal porosity. As can be seen from Fig. 1, the volume particle diameter distribution

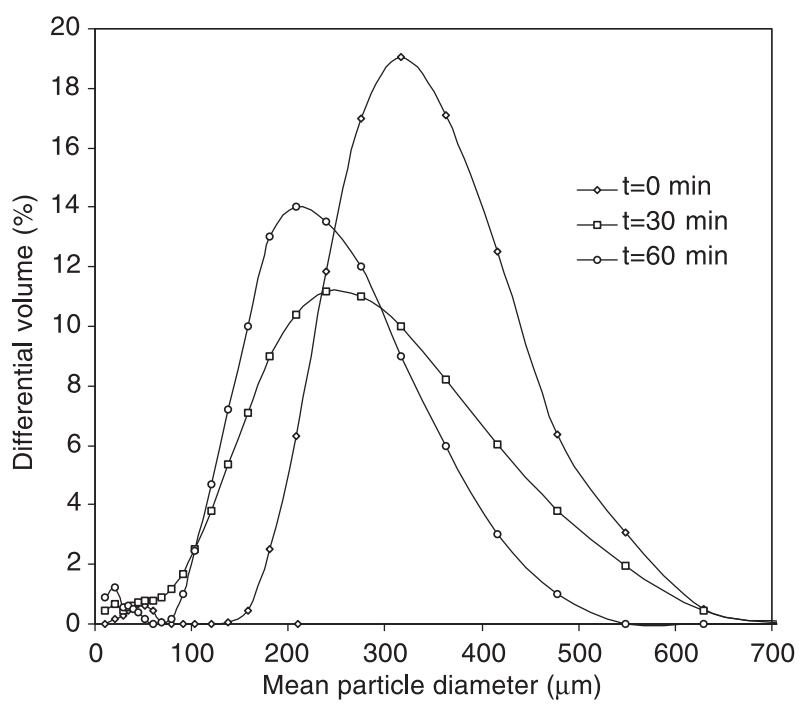

Fig. 1. Size distribution of the solid particles at different reaction times $\left(R_{\mathrm{p}}=153.75 \mu \mathrm{m}, T=220{ }^{\circ} \mathrm{C}\right.$ and initial $\mathrm{OH}^{-}$molality $=$ $\left.12.5 \mathrm{~mol} \mathrm{~kg}^{-1}\right)$. 
(A) initial particle

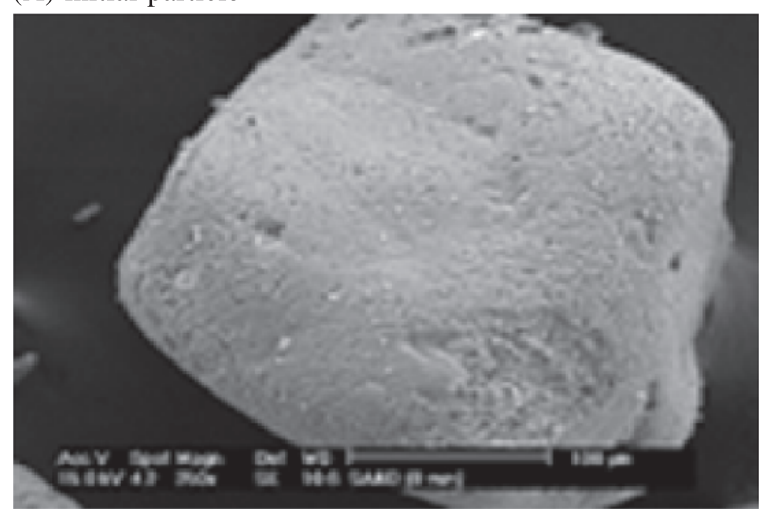

(B) reacted particle $\mathrm{t}=30 \mathrm{~min}$.

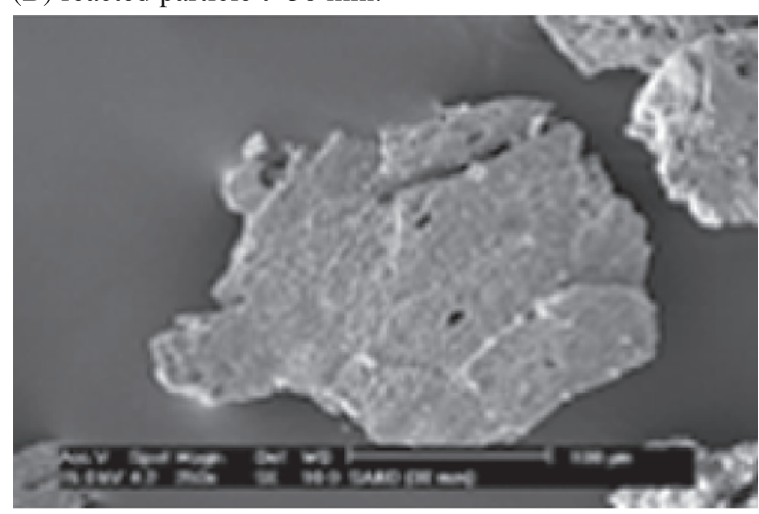

(C) reacted particle $\mathrm{t}=60 \mathrm{~min}$

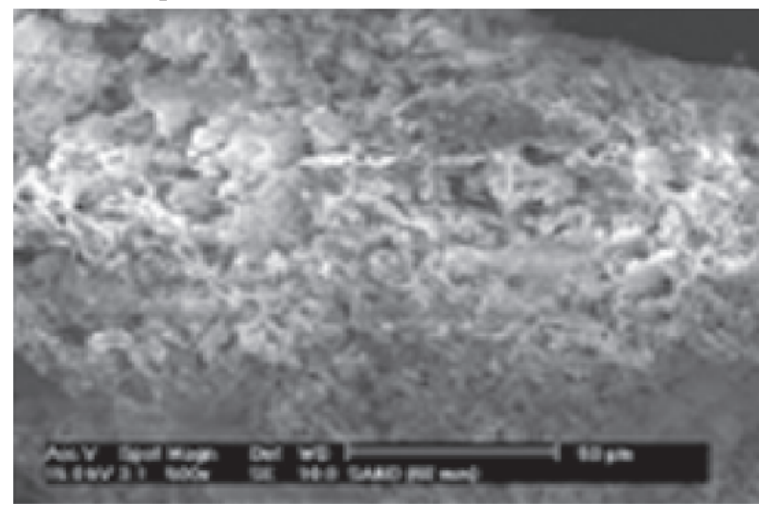

Fig. 2. SEM observations of the solid residue at different reaction times $\left(R_{\mathrm{p}}=153.75 \mu \mathrm{m}, T=220{ }^{\circ} \mathrm{C}\right.$ and initial $\mathrm{OH}^{-}$molality $=$ $\left.12.5 \mathrm{~mol} \mathrm{~kg}^{-1}\right)$.

was narrow and mono-modal. The volume diameter is about $240 \mu \mathrm{m}$ after $1 \mathrm{~h}$ apparent reaction time.

Scanning electron microscope observations of the raw and solid residue samples showed that the basic form and shape were slightly affected by the dissolution. However, the surfaces of grains become rougher with small pores and cracks particularly for the sample with a high conversion (see Fig. 2). The dissolution seems like a pitting corrosion process.

From the results obtained, it was reasonable to conclude that the dissolution occurred at first at the outer skin of the particle and the zone reaction would move into the solid state. Then, the particle shrank in size during dissolution. This should deter us to test the standard shrinking core model or an opportunely modified translation for the modelling investigation.

\subsection{Effect of reaction temperature}

In this section, our experiments were carried out in the temperature range $150-220{ }^{\circ} \mathrm{C}$, maintaining the particle size constant at $R_{\mathrm{p}}=153.75 \mu \mathrm{m}$ and the sodium hydroxide solution at $12.5 \mathrm{~mol} \mathrm{~kg}{ }^{-1}$.

For all experimental investigations, the real time of reaction will be given by $t=\theta+\theta_{0} . \theta_{0}$ represents the time that is required for the reaction to reach a conversion of $\alpha_{0}$, and $\theta$ is the apparent reaction time. Values of $\theta_{0}$ used in this work were from our previous works (Jendoubi et al., 1997, 1998). The heat-up period was about $30 \mathrm{~min}$ from the room temperature

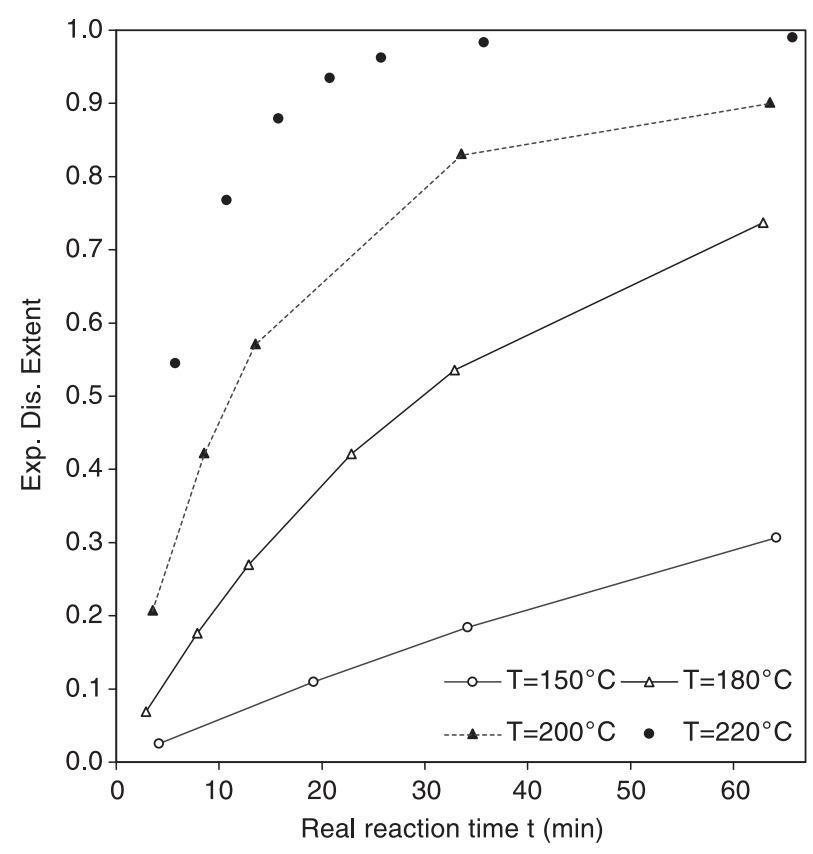

Fig. 3. Time evolution of the fraction transformed $(\alpha)$ at different temperatures $\left(R_{\mathrm{p}}=153.75 \mu \mathrm{m}\right.$ and initial $\mathrm{OH}^{-}$molality $=$ $\left.12.5 \mathrm{~mol} \mathrm{~kg}^{-1}\right)$. 


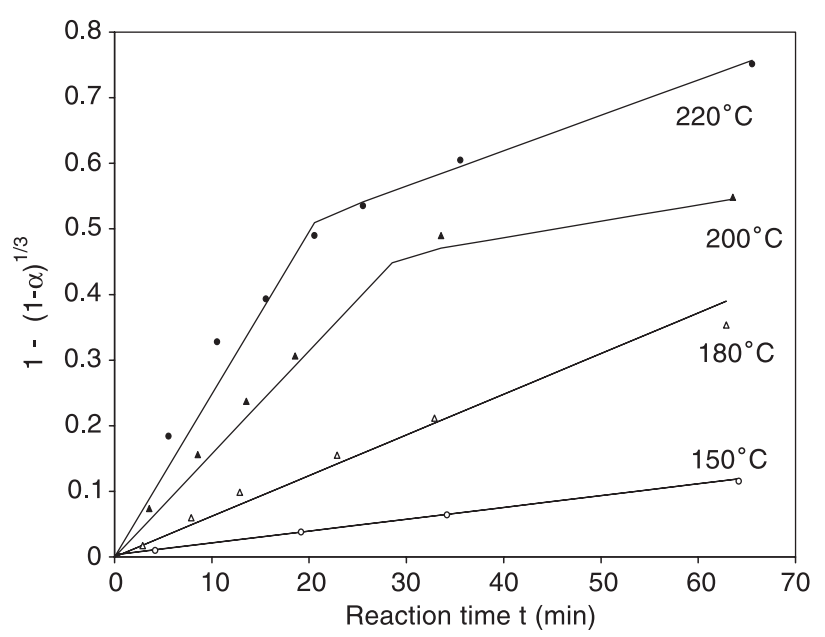

Fig. 4. Plot of $1-(1-\alpha)^{1 / 3}$ versus real reaction time at different temperatures $\left(R_{\mathrm{p}}=153.75 \mu \mathrm{m}\right.$ and initial $\mathrm{OH}^{-}$molality $\left.=12.5 \mathrm{~mol} \mathrm{~kg}^{-1}\right)$.

to the target temperature. The dissolution of sand can begin at about $150{ }^{\circ} \mathrm{C}$. Values of $\theta_{0}$ were in the range of 3-7 min. As seen from the experimental results given in Fig. 3, the dissolution rate increased with the increasing temperature.

In the case of the classical shrinking core model $\left(1-(1-\alpha)^{1 / 3}\right)=k t$, the time $t$ for a certain fraction

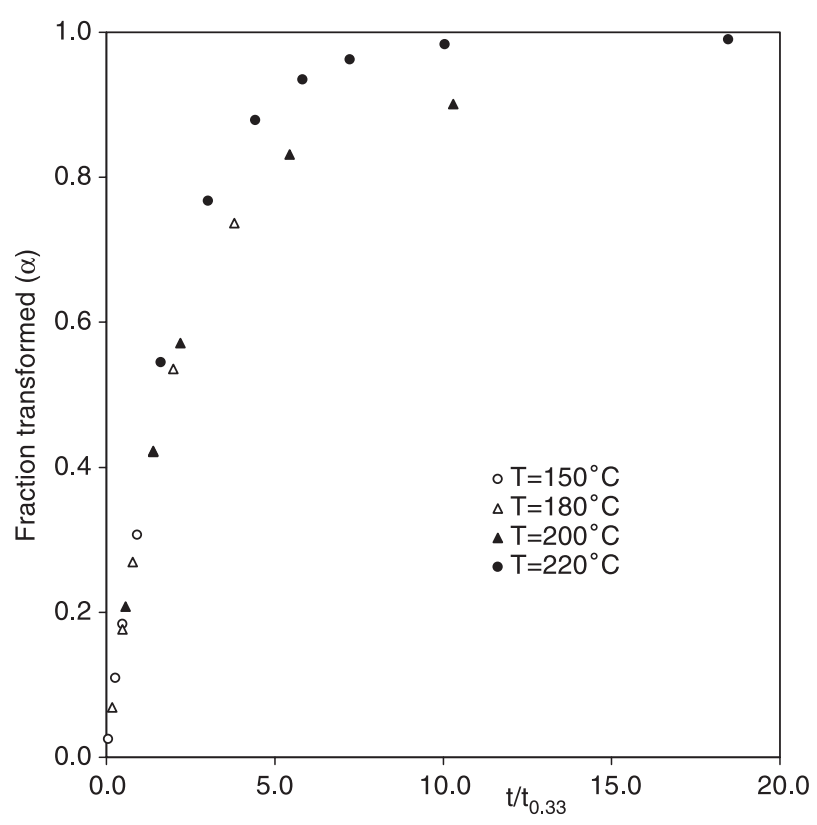

Fig. 5. Reduced time plots $\left(t / t_{0.33}\right)$ for the dissolution of sand at 150 , 180, 200 and $220{ }^{\circ} \mathrm{C} \quad\left(R_{\mathrm{p}}=153.75 \mu \mathrm{m}\right.$ and initial $\mathrm{OH}^{-}$ molality $=12.5 \mathrm{~mol} \mathrm{~kg}^{-1}$ ).

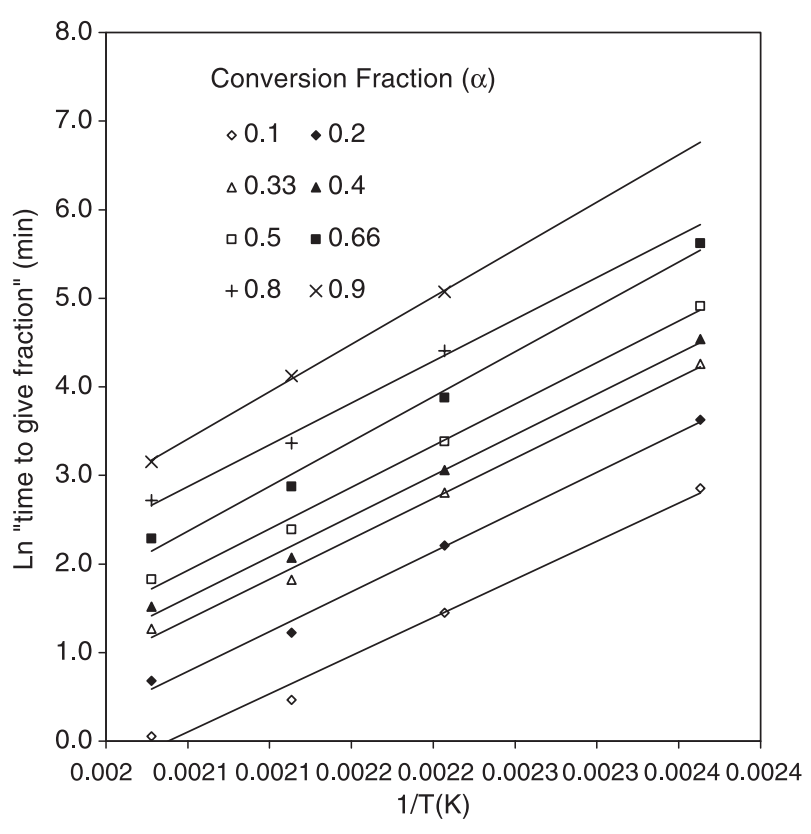

Fig. 6. Plot of $\ln$ "time to given fraction" versus $1 / T(\mathrm{~K})$.

transformed $\alpha$ can be determined from a set of isothermal experiments using

$\ln t=$ Const $+\frac{E_{\mathrm{a}}}{R T}$

In agreement with the validity of the Arrhenius equation, a plot of $\ln t$ against $1 / T$ gives straight lines.

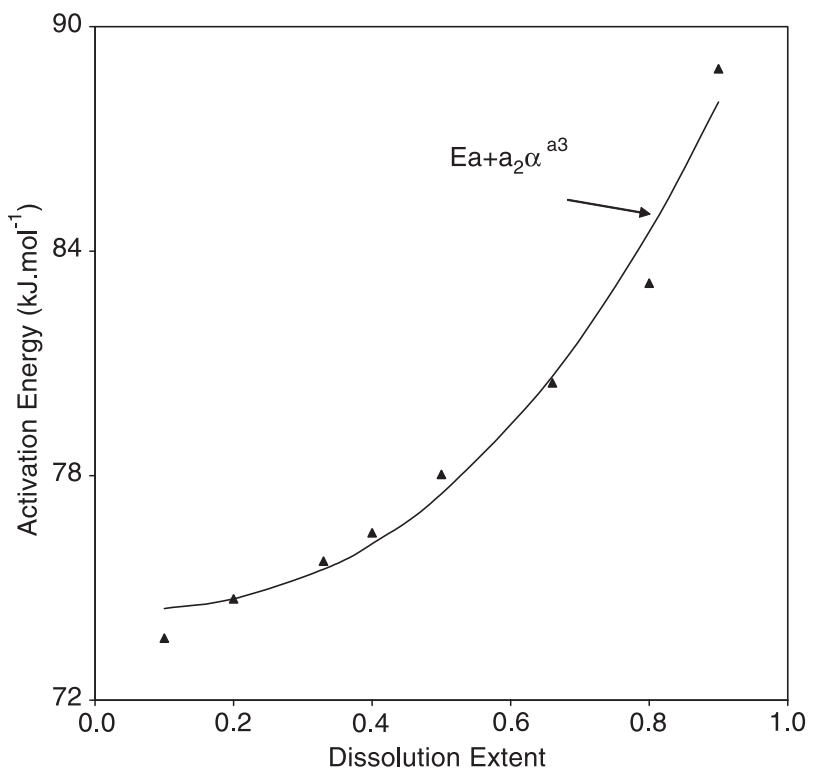

Fig. 7. Plot of the "variable activation energy" term against dissolution extent $(\alpha)$. 


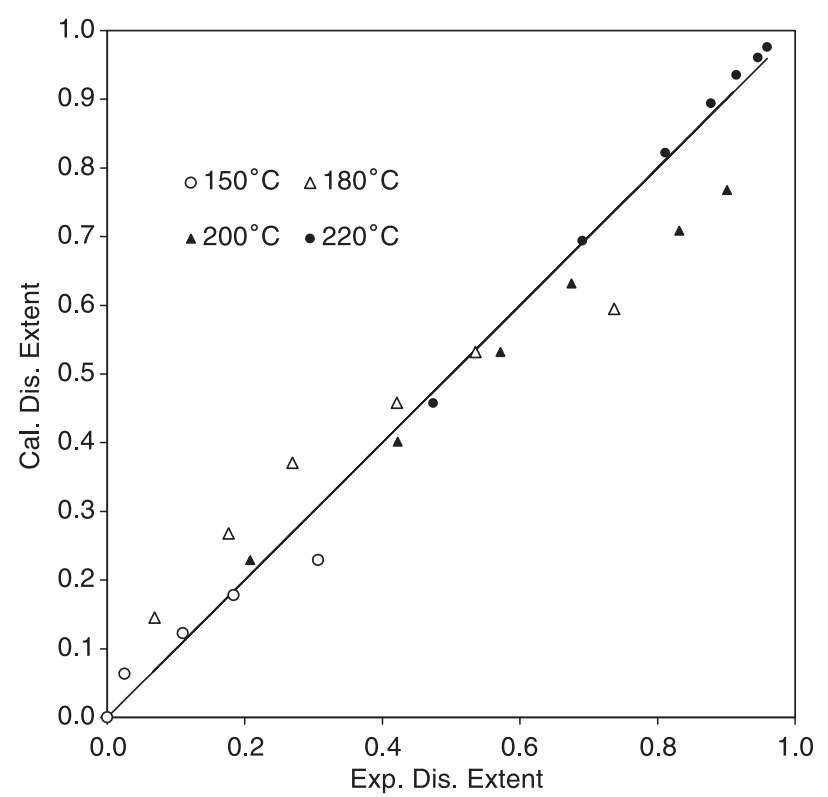

Fig. 8. Scatter diagram between the experimental extent of dissolution and those calculated using the modified shrinking core model. Runs performed at different temperatures $\left(R_{\mathrm{p}}=153.75 \mu \mathrm{m}\right.$ and initial $\mathrm{OH}^{-}$molality $=12.5 \mathrm{~mol} \mathrm{~kg}^{-1}$ ).

We observed (see Fig. 4) that the standard formalism of this model fits only the experimental data up to real dissolution time of about $25 \mathrm{~min}$ (heating time not included), especially for the two highest temperatures $\left(200\right.$ and $\left.220{ }^{\circ} \mathrm{C}\right)$. At these temperatures and at higher values of $\alpha>0.7$, the liquid phase became more viscous, and we can assume that the dominating reaction processes was not a single rate-controlling step. According to Levenspiel (1972), a change in activation energy indicates a shift in controlling mechanism of reaction.

The reduced time method was used in this context for the kinetic analysis of the experimental data in the temperature range $150-220{ }^{\circ} \mathrm{C}$. This method compares the experimental data in the form of fraction reacted against reduced time $t / t_{i}$ at definite $\alpha$ levels; with data calculated using a known solid-state reaction equation rate. The reduced time plots represented in Fig. 5 use $t / t_{0.33}$. Frequently, $t / t_{0.5}$ has been employed as well as $t / t_{0.66}$, but in this work, $t / t_{0.33}$ was applied for the data at $150{ }^{\circ} \mathrm{C}$ since $t_{0.5}$ could not been determined from the experimental data. As it can be seen from Fig. 5, experimental runs at different temperatures do not show a line on a single curve especially for greatest dissolution extent $\alpha(\alpha>0.5)$. That implies that a variation in the energetics of the reaction occurs throughout the transition.

The activation energy can be determined from rate constant $k$ or using the "time to a given fraction" method. The latter method was used by several authors (Redfern, 1987; Bray and Redfern, 2001 and references therein). Drawing $\ln t$ against $1 / T$ for higher values of $\alpha\left(0.8<\alpha<0.9\right.$ and $\left.100<T<130{ }^{\circ} \mathrm{C}\right)$, Bray and Redfern (2001) obtained straight lines with different slopes and concluded that the dominant mechanism of Ca-montmorillonite dehydration changed.

As seen in Fig. 6 the plots of $\ln$ "time to a given fraction" versus $1 / T$, for $0.1 \leq \alpha \leq 0.9$ and $150 \leq$ $T \leq 220{ }^{\circ} \mathrm{C}$ give straight lines with different slopes showing the dependence of the activation energy on $\alpha$. Points representative of conversions from 0.1 to 0.9 presented in this figure were calculated using the simple first-order exponential function developed elsewhere (Jendoubi et al., 1997). The variation of activation energy against the dissolution extent is illustrated in Fig. 7. It was found that the activation energy associated to the reaction can be expressed by an empirical equation of the form

$E_{\mathrm{a}}(\alpha)=E_{\mathrm{a}}+a_{2} \alpha^{a_{3}}$

where $E_{\mathrm{a}}, a_{2}$ and $a_{3}$ are adjustable parameters. The value of $E_{\mathrm{a}}=74.39 \mathrm{~kJ} \mathrm{~mol}^{-1}$ falls well within $67-77$ $\mathrm{kJ} \mathrm{mol}^{-1}$ reported by Rimstidt and Barnes (1980). It is possible to observe from Fig. 7 that there is quite good agreement between experimental and calculated results.

The approach applied by Brittan (1975) and Vegliò et al. (2001a) was used to take into account the variation of the activation energy with extent of dissolution, and the consumption of $\mathrm{NaOH}$ and over time in the data analysis. The proposed kinetic

Table 3

Estimated parameters (test: $1-7$ )

\begin{tabular}{llllll}
\hline Parameter & $a_{1}\left(\mu \mathrm{m} \mathrm{M}^{-b} \mathrm{~min}^{-1}\right)$ & $E_{\mathrm{a}}(\mathrm{kJ} / \mathrm{mol})$ & $a_{2}(\mathrm{~kJ} / \mathrm{mol})$ & $a_{3}$ & $b($ dimensionless $)$ \\
\hline Estimated value & $25.13 \pm 1.27$ & $74.39 \pm 5.50$ & $17.69 \pm 1.34$ & $2.5 \pm 1.5$ & $0.455 \pm 0.04$ \\
\hline
\end{tabular}


equation including four adjustable parameters (Eq. (6)) was numerically solved by the Runge Kutta method, and the parameters were fitted by the nonlinear regression analysis using the solver program of Microsoft Excel with Newton's method. At the beginning, only the database performed at different temperatures were incorporated in the data treatment.

The objective function used was based on a relative deviation between calculated and experimental extent of dissolution and the absolute mean square errors (ER) was calculated by the following equation:

$\mathrm{ER}=\left[\frac{1}{N} \sum_{i=1}^{N}\left(\alpha_{i, \exp }-\alpha_{i, \text { cal }}\right)^{2}\right]^{1 / 2}$

where $N$ is the number of experimental data and $i$ is the experimental conversion index.

The precision obtained for the data representation was better than $7 \%$. A comparison between the experimental dissolution extents collected at different temperatures and the simulated data is shown in Fig. 8. As it can be seen, there is an agreement

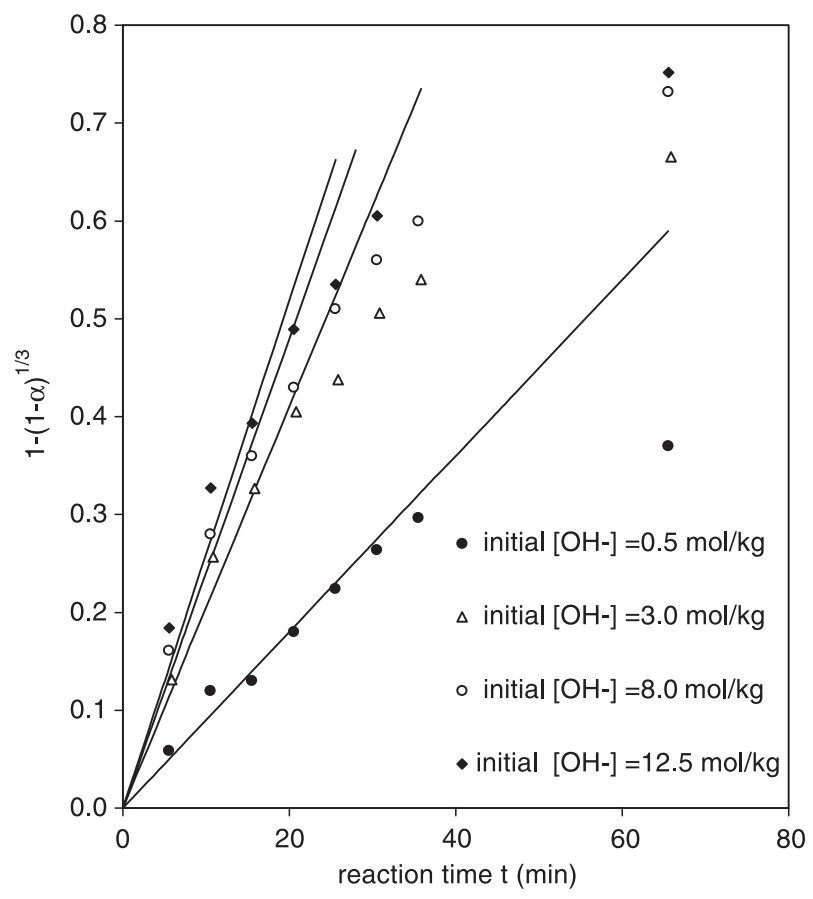

Fig. 9. Plot of $1-(1-\alpha)^{1 / 3}$ versus time for different ion hydroxide molalities $\left(R_{\mathrm{p}}=153.75 \mu \mathrm{m}\right.$ and $\left.T=220^{\circ} \mathrm{C}\right)$.

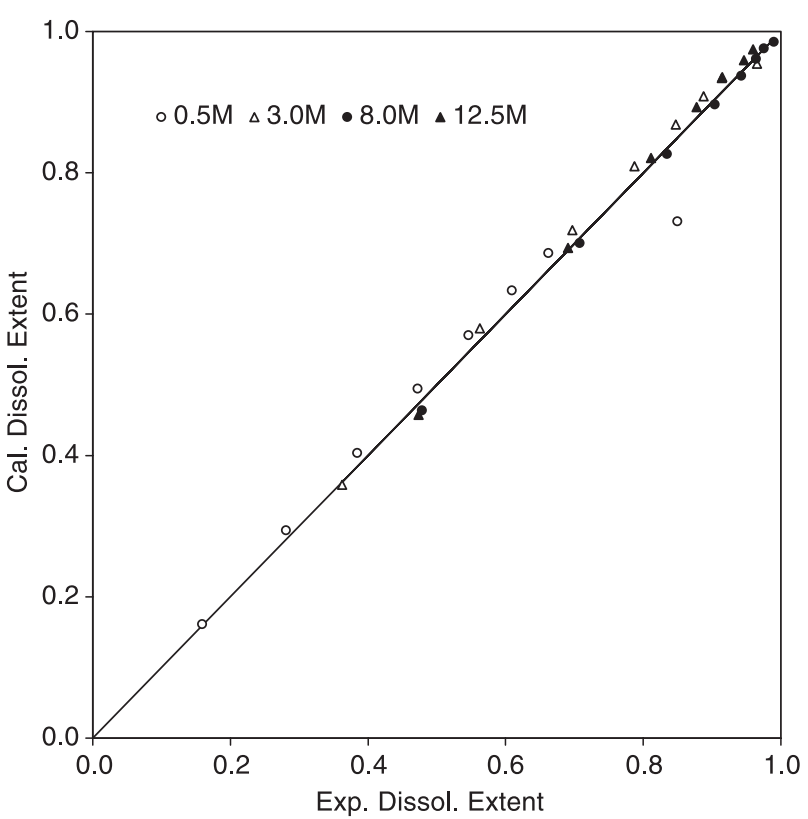

Fig. 10. Scatter diagram between the experimental extent of dissolution and those calculated using the modified shrinking core model. Effect of ion hydroxide molality $\left(R_{\mathrm{p}}=153.75 \mu \mathrm{m}\right.$ and $\left.T=220{ }^{\circ} \mathrm{C}\right)$.

between simulated and experimental results. The final values of the adjusted parameters are summarized in Table 3.

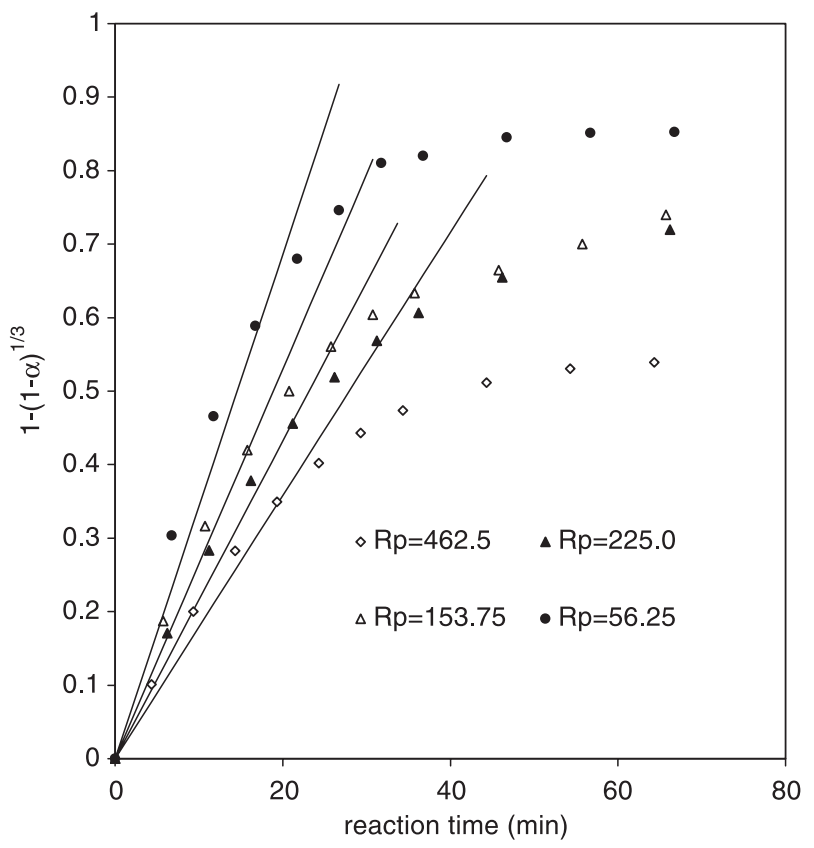

Fig. 11. Plot of $1-(1-\alpha)^{1 / 3}$ versus real dissolution time for different particle sizes $\left(T=220^{\circ} \mathrm{C}\right.$ and initial $\mathrm{OH}^{-}$molality $\left.=12.5 \mathrm{~mol} \mathrm{~kg}^{-1}\right)$. 


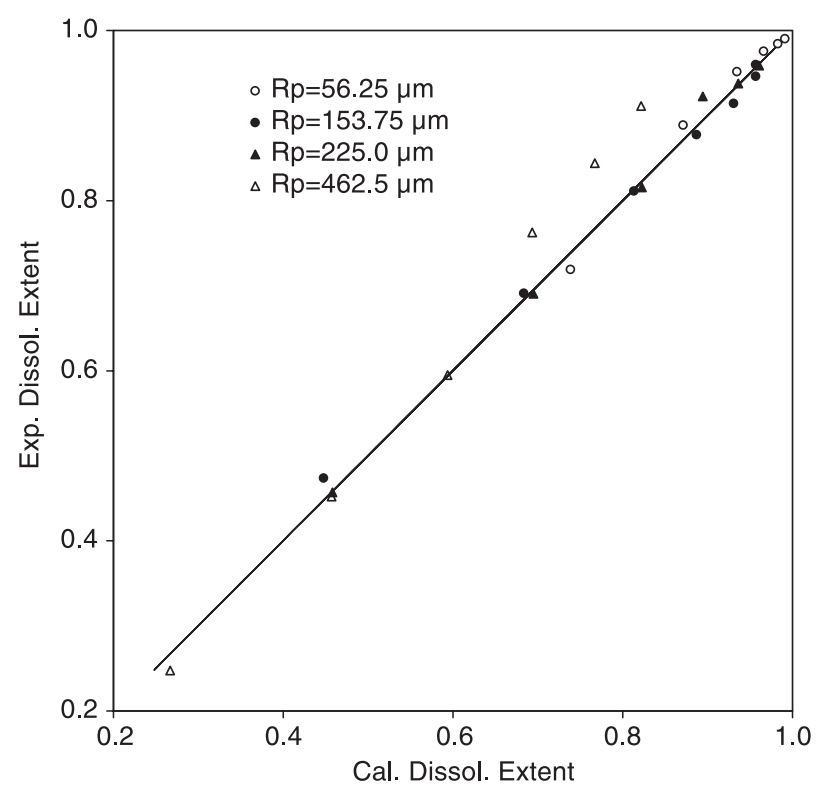

Fig. 12. Scatter diagram between the experimental extent of dissolution and those calculated using the modified shrinking core model. Effect of particle size $\left(T=220{ }^{\circ} \mathrm{C}\right.$ and initial $\mathrm{OH}^{-}$ molality $=12.5 \mathrm{~mol} \mathrm{~kg}^{-1}$ ).

\subsection{Effect of $\mathrm{OH}^{-}$molality at constant particle size}

Experiments were performed at $220{ }^{\circ} \mathrm{C}$ and with particles in the size range $(+300,-315) \mu \mathrm{m}$ to investigate the effect of $\mathrm{OH}^{-}$on the dissolution rate. As is possible to observe from Fig. 9, the shrinking core model cannot be employed to fit the kinetic data at different $\mathrm{OH}^{-}$molalities. However, considering the variation of the reagent concentration during dissolution (using VAESCM), the agreement between experimental and calculated conversion values was found to be very good (see Fig. 10).

The prediction of dissolution extent at different ion hydroxide molalities is characterized by an rms absolute deviation less than $8 \%$. This satisfactory agreement was obtained by using the values reported in Table 3 without new adjusted parameters.
The reaction order with respect to hydroxide ion is 0.45. In the study carried out by Worley et al. (1996), it was reported that the value of the reaction order with respect to $\mathrm{OH}^{-}$depends on the temperature of dissolution and lies between 0.72 at $100{ }^{\circ} \mathrm{C}$ and 0.88 at $200{ }^{\circ} \mathrm{C}$.

\subsection{The effect of particle size}

Experiments were carried out using four different particle size ranges: $(+100,-125),(+300,-315)$, $(+400,-500)$ and $(+850-1000) \mu \mathrm{m}$, while other parameters were kept constant: temperature at $220{ }^{\circ} \mathrm{C}$ and sodium hydroxide molality at $12.5 \mathrm{~mol} \mathrm{~kg}^{-1}$.

The effect of the particle size on the sand dissolution is illustrated in Fig. 11. From this figure, one can see that the rate of dissolution increased by decreasing the initial particle radius noted $R_{\mathrm{p}}$ and the plots of $1-(1-\alpha)^{1 / 3}$ according to the standard shrinking core model versus real dissolution time gave two straight lines. So, the SCM used in the standard form was not able to describe the experimental data at different particle size. However, by applying the proposed model and readjusting only the parameter $a_{1}$, a good agreement was observed as it illustrated in Fig. 12. The obtained parameter and root mean square deviation for each particle size are reported in Table 4. The value of the adjustable parameter was expressed as $a_{1} / R_{\mathrm{p}}$ that normally decreases as the particle size increases.

\subsection{Kinetic analysis}

In this paragraph, attempts were made to fit all experimental data (runs at different temperatures, different particle sizes and reactant molality) to a series of a most commonly used solid-state reaction equations, summarized by Table 5. These functions are plotted as dotted lines for the diffusion group and continuous lines for the phase boundary with all

Table 4

Estimated parameters (test $8-10$ )

\begin{tabular}{lllll}
\hline Fraction size $\left(R_{\mathrm{p}} \mu \mathrm{m}\right)$ & 56.25 & 153.75 & 225.00 & 462.5 \\
\hline$a_{1} / R_{\mathrm{p}}\left(\mathrm{M}^{-0.45} \mathrm{~min}^{-1}\right)$ & $0.527 \pm 0.02$ & $0.158 \pm 0.006$ & $0.131 \pm 0.008$ & $0.053 \pm 0.01$ \\
rms $(\mathrm{pct})$ & 1.6 & 1.4 & 1.3 & 7.3 \\
\hline
\end{tabular}


experimental data in Fig. 13. In this figure, we have excluded certain reaction-controlling mechanisms. As can be seen from this figure, the kinetic equation of phase boundary (R2 and R3) is the best fit for the experimental dissolution extent less than 0.7. Over the greatest extent, data were intermediate between the value expected for phase boundary and that expected for diffusion control.

The above conversion time expressions (see Table 5) assume that a single resistance controls throughout dissolution of the sand particle. According to Levenspiel (1972), the relative importance of the film, ash layer diffusion and reaction steps will vary as dissolution progresses, and the time to reach any stage of conversion is the sum of the times needed if each resistance acted alone. Madsen et al. (1974) proposed the mixture model (layer diffusion + reaction) named reaction zone model for the leaching of lowgrade copper sulfide ores. The conversion time expression is

$$
\begin{aligned}
\frac{t}{\tau_{\text {reaction }}}= & \left(1-(1-\alpha)^{1 / 3}\right)+B\left(1-3(1-\alpha)^{\frac{2}{3}}\right. \\
& +2(1-\alpha))
\end{aligned}
$$

where $\tau_{\text {reaction }}$ is the complete dissolution time given by Eq. (5) and $B$ is a parameter function of $D_{\mathrm{e}}$ the effective diffusion coefficient in a solid $\left(\mathrm{cm}^{2} \mathrm{~s}^{-1}\right)$, the rate constant, $R_{\mathrm{p}}$, the initial radius of particle. Value of the parameter $(B=2.62)$ was estimated by a nonlinear regression analysis procedure. As it can be seen from Fig. 13, this model seems to be more suitable to describe the dissolution of sand particles into alkaline solutions. In the future, experimental

Table 5

\begin{tabular}{|c|c|}
\hline Mechanism & Kinetic equation \\
\hline $\begin{array}{l}\mathrm{R} 2 \text { - phase boundary } \\
\text { reaction cylindrical }\end{array}$ & $1-(1-\alpha)^{1 / 2}=k t$ \\
\hline $\begin{array}{l}\mathrm{R} 3 \text { - phase boundary } \\
\text { reaction spherical }\end{array}$ & $1-(1-\alpha)^{1 / 3}=k t$ \\
\hline $\begin{array}{l}\text { D1-one-dimensional } \\
\text { diffusion }\end{array}$ & $\alpha^{2}=k t$ \\
\hline $\begin{array}{l}\text { D3 - three-dimensional } \\
\text { diffusion, spherical }\end{array}$ & {$\left[1-(1-\alpha)^{1 / 2}\right]^{2}=k t$} \\
\hline $\begin{array}{l}\text { D4-three-dimensional } \\
\text { diffusion, spherical }\end{array}$ & $(1-2 / 3 \alpha)-(1-\alpha)^{2 / 3}=k t$ \\
\hline
\end{tabular}

Solid-state reaction equations used in this work

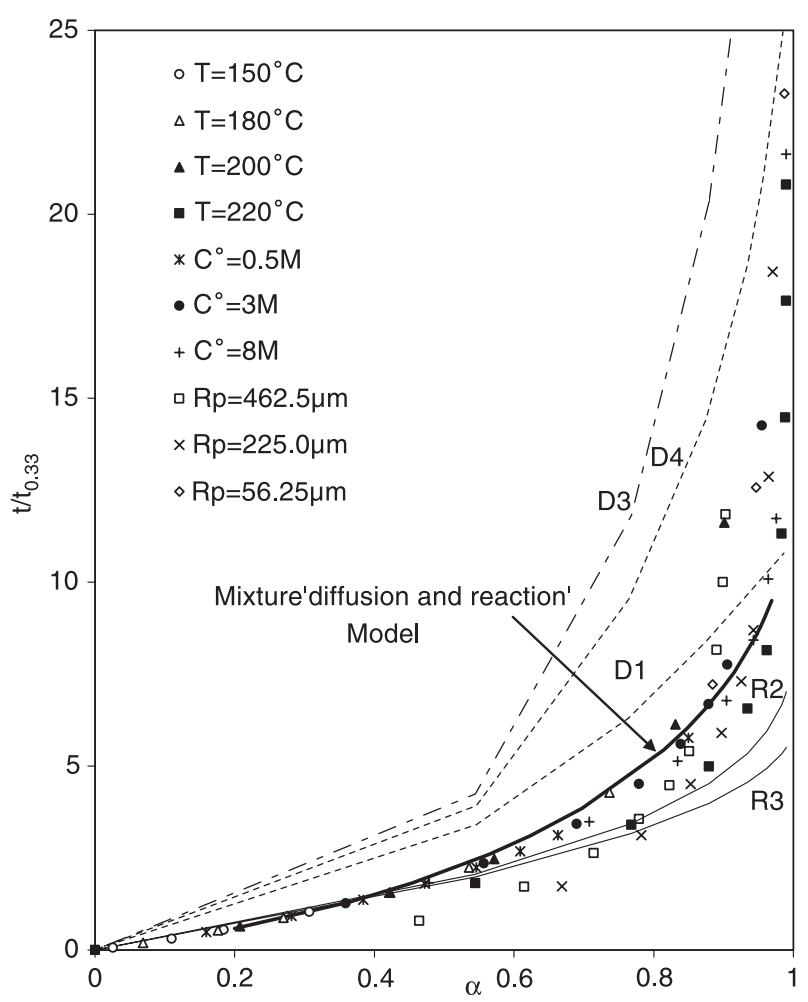

Fig. 13. Plots of the model outlined in Table 5 along with total data points performed at different temperatures, different particle sizes and different hydroxide ion molalities.

data obtained at different stirring speed would be included in the database to obtain reliable kinetic results according to the mixture model.

\section{Conclusions}

The dissolution of natural sand into alkaline solutions at high $T$ and $P$ was investigated by taking into consideration the parameters of temperature, particle size and hydroxide ion molality. The kinetic data fit well to the shrinking core model with variable activation energy. A good agreement between the experimental results performed at different temperatures and calculated data have been obtained with a root mean squares (rms) absolute deviation less than $7 \%$. A satisfactory representation of experimental data at different ion hydroxide molalities was obtained and the rms absolute deviation was less than $6 \%$. On the basis of these results, we have extended the representation to the experimental data performed at different particle sizes, and the best fit was obtained by adjust- 
ing one parameter $\left(a_{1}\right)$ and considering one fraction size at a time.

The kinetic analysis proved that the nature of the rate-controlling mechanism was a function of the extent of dissolution, and the reaction was dominated by a combination of two processes (phase boundary and diffusion). The present work is being extended in two directions:

- experimental results on the effect of stirring speed will be included in the database in order to check the effect of diffusion on the reaction rate.

- development of a full model including the evolution of the grain topology and a mixture of particles of various shapes and sizes.

\section{List of symbols}

$a_{1} \quad$ constant in Eq. (6) $\left(\mu \mathrm{m} \mathrm{M}^{-b} \min ^{-1}\right)$

$a_{2} \quad$ adjustable parameter in Eqs. (6) and (9) (kJ $\mathrm{mol}^{-1}$ )

$a_{3} \quad$ adjustable parameter in Eqs. (6) and (9) (dimensionless)

$b$ reaction order with the respect to the ion hydroxide

$C_{\mathrm{OH}^{-}}^{0} \quad$ the initial hydroxide ion molality (mol $\mathrm{cm}^{-3}$ )

$C_{\mathrm{OH}^{-}}^{\mathrm{st}}$ the stoichiometric hydroxide ion molality $\left(\mathrm{mol} \mathrm{cm} \mathrm{cm}^{-3}\right.$ )

$D_{\mathrm{e}} \quad$ the effective diffusion coefficient in a solid $\left(\mathrm{cm}^{2} \mathrm{~s}^{-1}\right)$

$E_{\mathrm{a}} \quad$ activation energy $\left(\mathrm{kJ} \mathrm{mol}^{-1}\right)$

$k$ the rate constant $\left(\mathrm{mol} \mathrm{min}{ }^{-1}\right)$

$k^{\circ} \quad$ a constant factor in Eq. (3)

$m \quad$ mass of sand at time $t(\mathrm{~g})$

$m_{0} \quad$ initial mass of sand $(\mathrm{g})$

$M_{\mathrm{SiO}_{2}} \quad$ molecular weight $\left(\mathrm{g} \mathrm{mol}^{-1}\right)$

$r \quad$ rate of dissolution

$R \quad$ universal gas constant $\left(\mathrm{J} \mathrm{mol}^{-1} \mathrm{~K}^{-1}\right)$

$R_{\mathrm{p}} \quad$ mean particle radius $(\mathrm{cm})$

$S \quad$ surface area $\left(\mathrm{cm}^{2} \mathrm{~g}^{-1}\right)$

$t$ real reaction time $(\mathrm{min})$

$T \quad$ absolute temperature $(\mathrm{K})$

$T^{\prime} \quad$ absolute reference temperature $(\mathrm{K})$

\section{Greek letters}

$\alpha \quad$ extent of dissolution (dimensionless)

$v \quad$ stoichiometric coefficient

$\rho_{\mathrm{SiO}_{2}} \quad$ true density of sand $\left(\mathrm{g} \mathrm{cm}^{-3}\right)$ complete dissolution time ( $\mathrm{min}$ )

apparent reaction time (min)

\section{Acknowledgements}

The authors would like to thank Professor F. Vegliò, Genoa Albaro Italy for his valuable discussions and literature. The authors express their profound gratitude to the editor and reviewers of Hydrometallurgy for corrections and suggestions.

\section{References}

Bartlett, R.W., 1973. In: Evans, D.J.I., Shoemaker, R.S. (Eds.), Int. Symp. on Hydrometallurgy. AIME, New York, pp. 331-374.

Ben Brahim, F., Mgaidi, A., El Maaoui, M., 1997. Exploration of mesoporous structure of Tunisian Raw and acid leached phosphate ore particles. Can. J. Chem. Eng. 75, 759-764.

Ben Brahim, F., Mgaidi, A., El Maaoui, M., 1999. Kinetics of leaching of phosphate ore particles in dilute phosphoric acid solutions. Can. J. Chem. Eng. 77, 136-142.

Bray, H.J., Redfern, S.A.T., 2001. Kinetics of dehydration of Camontmorillonite. Phys. Chem. Miner. 26, 591-600.

Brittan, M.I., 1975. Variable activation energy model for leaching kinetics. Int. J. Miner. Process. 2, 321-331.

Dixon, D.G., Hendrix, J.L., 1993. A general model for leaching of one or more solid reactants from porous particles. Metall. Trans. B 24, 157-169.

Fonseca, A.M., Orfao, J.J., Salcedo, R.L., 1998. Kinetic modelling of the reaction of $\mathrm{HCl}$ and solid lime at low temperature. Ind. Eng. Chem. Res. 37, 4570-4576.

Georgiou, D., Papangelakis, V.G., 1998. Sulphuric acid pressure leaching of a limonitic laterite: chemistry and kinetics. Hydrometallurgy 49, $23-46$.

Greg, W.D., Lawrence, R.G., Lawson, P.J., Rideout, J.A., 2000. Application of the shrinking core model to the kinetics of extraction of gold (I), silver (I) and nickel (II) cyanide complexes by novel anion exchange resins. Hydrometallurgy 56 (3), 323-336.

Jendoubi, F., Mgaidi, A., El Maaoui, M., 1997. Kinetics of the dissolution of silica in aqueous sodium hydroxide solutions at high pressure and temperature. Can. J. Chem. Eng. 75 (4), $721-727$.

Jendoubi, F., Mgaidi, A., El Maaoui, M., 1998. The dissolution kinetics of sand as function of particle size. Can. J. Chem. Eng. 76 (2), 233-238.

Lakatos, B., Blickle, T., 1990. Effect of particle size distribution on liquid-solid reaction kinetics in solutions. Acta Chim. Hung. 127 (3), 395-405.

Levenspiel, O., 1972. Chemical Reaction Engineering, 2nd ed. Wiley, New York.

Lubej, A., Koloini, T., Pohar, C., 1999. Kinetics of the dissolution of copper (II) in diluted aqueous hydrochloric acid solutions at different temperature. Ind. Eng. Chem. Res. 38, 4277-4283. 
Madsen, B.W., et al., 1974. Application of a mixed kinetics model to leaching of low grade copper sulphide ores. Trans. Soc. Min. Eng. 258, 69-74.

Rahman, S.U., Al-Saleh, M.A., 1999. Kinetic study of leaching process of Raney silver catalyst. Chem. Eng. J. 72, 229-233.

Redfern, S.A.T., 1987. Kinetics of dehydration of kaolinite. Clay Miner. 22, 447-456.

Rimstidt, J.D., Barnes, H.L., 1980. The kinetic of silica-water reactions. Geochim. Cosmochim. Acta 44, 1683-1699.

Vegliò, F., Trifoni, M., Pagnanelli, F., Toro, L., 2001a. Shrinking core model with variable activation energy: kinetics of maganiferous ore leaching with sulfuric acid and lactose. Hydrometallurgy $60,167-179$.
Vegliò, F., Trifoni, M., Toro, L., 2001b. Leaching of Manganiferous ores by glucose in sulfuric acid solutions: kinetic modelling and related statistical analysis. Ind. Eng. Chem. Res. 40, 3895-3901.

Villermaux, J., 1982. Génie de la réaction Chimique conception et fonctionnement des réacteurs, 2nd ed. Lavoisier, Paris.

Worley, W.G., Tester, J.W., Grigsby, 1996. Quartz dissolution kinetics from $100-200^{\circ} \mathrm{C}$ as a function of $\mathrm{pH}$ and ionic strength. A.I.Ch.E. J. 42 (12), 3442-3457.

Yoshioka, T., Motoki, T., Okuwaki, A., 2001. Kinetics of hydrolysis of poly(ethylene terephtalate) powder in sulphuric acid by a modified shrinking core model. Ind. Eng. Chem. Res. 40, $75-79$. 